\title{
Relational arenas in a regional Higher Education system: Insights from an empirical analysis
}

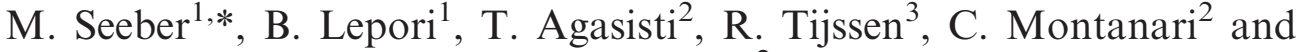 \\ G. Catalano ${ }^{2}$ \\ ${ }^{1}$ CORE, University of Lugano, Via Lambertenghi 10, 6904 Lugano, Switzerland, ${ }^{2}$ Department of \\ Economics, management and Industrial Engineering, Politecnico di Milano, Via Lambruschini 4 B, \\ 20156 Milano, Italy and ${ }^{3}$ CWTS, Faculty of Social and Behavioural Science, \\ University of Leiden, 2300 Leiden, the Netherlands \\ *Corresponding author. Email: marco.seeber@usi.ch.
}

\begin{abstract}
Extant indicators on research and higher education do not consider the complex relational structure in which universities are embedded and that influences their performance on one side, and the impact of policies on the other. This article investigates the overall pattern of universities' relational arenas in a Regional environment by considering their two main domains of activity, namely research and teaching. We study their structure, determinants, and existing interactions, in order to understand the possible consequences for policy making and management, and to identify synthetic indicators to represent them.
\end{abstract}

Keywords: teaching; research; cooperation; competition; region; relationships.

\section{Introduction}

In the recent years, indicators on higher education institutions witnessed a very rapid development; traditional indicators focused on educational activities and R\&D expenditures (Bonaccorsi et al., 2007) have been complemented by measures of research production and quality, for example through bibliometric analysis, as well as of knowledge and transfer activities (Gulbrandsen and Slipersaeter, 2007). More recently, new concepts have been put forward to systematically compare university activity profiles, taking into account the multi-dimensional nature of universities (Van Vught 2009). However, most available indicators do not take into account the relational structure in which universities are embedded, thus ignoring a fundamental dimension of the Higher Education field. Academic activities do not develop in isolation, but rather imply several relationships within and beyond the institution, that have a large impact on opportunities and performances. Policies that do not consider the relational dimension of the universities risk to biased or even counter-productive (Stokman, 2011).
HE and research studies have analysed the relational dimension mostly at the individual or group level, but essentially focusing on international research collaborations. However, we first argue that teaching and research activities are highly interconnected and then the simultaneous analysis of these two relational arenas in the same institutional and geographical space is needed to provide an overall understanding of HEIs positioning. Second, although international competition is certainly important, most of the relationship of universities takes place in a national or regional context and understanding relational structure in these spaces is highly relevant for designing public policies.

Thus, the purpose of this article is twofold. First, to analyse a regional higher education relational spaces, in research and teaching, their main determinants and interplay. Second, to identify synthetic indicators to represent the position of each actor and the relationships between actors. The article is based on an integrated approach that makes use of several measures, and we consider the case study of Lombardy, the largest Italian Region. 
The article is organized as follows. The first section introduces the theoretical framework and develops hypotheses on the structure and determinants of the research and teaching arenas. The second section describes the main characteristics of the Lombardy HE System and its main actors. The third section analyses the relational arenas and presents empirical results. The fourth section discusses the main results, as well as implications for policy making.

\section{The relational arenas of the HEls}

Relationships between organizations located in a similar environment are multifaceted. Organizations are likely to compete when their survival depends on a similar set of resources and their pattern of relationships with other actors is similar (Hannan and Freeman, 1989; Burt, 1992; Carroll and Hannan, 2000). However, the same spaces supporting competitive relationships also represent the backbone of cooperation (Hoskisson et al., 1999; Barnett, 2006; Ingram and Yue, 2008).

The HE system is highly institutionalized in comparison with market environments. Even though, there is increasing evidence of intense competitive and cooperative relationships. A simple way to characterize the relationships between universities is to consider them in the frame of the type of activity, research, and teaching, which imply different types of relations and are managed at different levels. The following paragraphs develop hypotheses as to the determinants these relationships, the resulting overall patterns at institutional level and the interactions between these two arenas.

Clearly, universities are multilevel organizations and thus collaboration and competition take place at different levels, including individuals, research groups, departments, and whole universities (Deiaco et al., 2010). In this article, we focus on the university level, even if we include a control for disciplinary composition: this choice is supported by the growing body of literature showing that universities are increasingly acting as organizations and corporate actors at the aggregated level (Bonaccorsi and Daraio, 2007; de Boer et al., 2007). We focus on measures of observed collaboration competition, but we do not contend that these are the outcome of intentional strategic decisions of the leadership; rather we observe empirically the outcome of the interaction between different organizational actors and we look for regularities which are related to specific organizational characteristics, like reputation, geographical position, etc. As a matter of fact, we are not observing directly competitive strategies of universities at the top-level, but rather structural determinants of market collaboration and competition 8 as an outcome of micro-level processes).

\subsection{Relationships in research}

Extant research shows that collaboration, at least at the individual and group level, is strongly associated with productivity and quality (Lee and Bozeman, 2005), not only because of the advantages in terms of complementarity of knowledge, cross-fertilization of ideas, etc. (Mulkay, 1972), but also because cooperation networks are key assets in competition for resources, for example in acquiring research projects. Although research cooperation is developed by individual researchers or groups; we focus on the aggregated patterns at the university level and its determinants.

In social network literature, the existence and strength of ties between two organizations have been explained through assortativity and proximity relational mechanisms (Rivera et al., 2010). Assortativity explains the creation of social relationships with the similarity, compatibility, and complementarity in the actors' attributes. Proximity mechanisms affect interactions because the likelihood of establishing relationships increases when two organizations share the same social, institutional, and geographical spaces. Boschma (2005) describes five proximity mechanisms that ease (or limit) collaboration between organizations. Cognitive proximity means that people sharing the same knowledge base and expertize may learn from each other, as it facilitates effective communication; but too much proximity can be detrimental to learning and innovation. Organizational proximity refers to the extent to which relations are shared in an organizational arrangement and spans in a continuum from no ties between independent actors, loosely coupled networks, to strong ties in a hierarchical structure; it favors innovation by reducing uncertainty and risk of opportunism, but too strong proximity reduces flexibility. Social proximity implies that relationships between actors involve trust, based on friendship, kinship, and experience. Institutional proximity occurs when actors share similar habits, routines, practices, laws, that regulate interactions. Finally, geographic proximity facilitates interaction and learning by stimulating the other dimensions of proximity.

Relationships between researchers and universities have been traditionally investigated through co-publications, co-patenting, and co-participation to projects, mostly European Framework programs (Breschi and Lissoni, 2004; Glänzel and Schubert, 2004; Noyons, 2004). These studies have confirmed the importance of assortativity and proximity mechanism: the several dimensions of proximity ease communication (Frenken et al., 2009), spatial proximity encourages collaboration by favoring informal communication (Hagstrom, 1965; Newman 2004; Klein 2008), the cost of collaborating across universities is higher for multi-disciplinary research (Cummings and Kiesler, 2005), and collaborations in projects is problematic when partners have dissimilar institutional structures, cultures, and norms (Olson and Olson, 2000; Cummings and 
Kiesler, 2007; Trochim et al., 2008;). In recent decades, research collaboration among researchers in different universities has increased steadily (Schubert and Braun, 1990; Braun and Glänzel, 1996; Glänzel, 2001; Wuchty et al., 2007). Between schools collaborations are particularly relevant for elite institutions (Jones et al., 2008). The average distance between collaborating universities has changed only slightly, while the reputation gap is of increasing importance in research collaborations, with an effect of social stratification in multi-university collaborations (Jones et al., 2008; Evans et al., 2011).

Some hypotheses emerge on the determinants of research collaborations in a regional context.

First, it may be argued that the position of the actors and the intensity of connections between them are largely determined by institutional size and discipline similarity. In fact, larger universities are likely to have a larger scientific production, granting them a more central position. This is particularly the case in the Italian system that shows weak differentiation in research productivity (Halffman, 2010). Moreover, research activity mostly organizes around disciplines, as they have peculiar research agendas, goals, codes, and frames (Whitley, 1984). Despite the increased emphasis on interdisciplinary research, discipline structures still have a profound impact on cognitive and social proximity, easing collaboration between scientists in the same field.

Geographic proximity is expected to have a weak role in co-publication, which tends to be increasingly geographically spread (Wagner, 2008), but a stronger influence for project collaborations, since coordination of projects is complex and requires some face-to-face interactions. Social proximity may be expected to have an important role, for instance when researchers move from one university to another during their career and develop long-lasting relationships. However, the investigation of similar mechanisms would require data on career patterns, which are difficult to obtain. Research productivity affects the number cooperation directly through the sheer size of research activities, and indirectly via the increased reputation, the external perception of quality in the community.

\subsection{The education arena}

In education, we consider that relationships are mostly competitive: students are an important source of funding and universities generally do not necessarily cooperate to offer courses. Two relevant streams of literature deal with determinants of student's choice on the one side, with factors affecting mobility of students on the other side.

Student's choice is conceived as a multistage process which runs from the (i) predisposition to continue education, to (ii) the gathering of information until the (iii) choice of a particular college. The choice is influenced by personal characteristics (ability, wealth, etc.), the communication efforts of the university and its characteristics
(Chapman, 1981; Hossler and Gallagher, 1987). Empirical studies show that the field/course of study is the prime factor affecting student's choice (Soutar and Turner, 2002; Maringe, 2006). Other factors are also influential, but work after the choice of the field of study: students tend to enroll at institutions with the lowest net cost (Coccari and Javalgi, 1995), most students attend universities close to home (Chapman, 1981; Kellaris and Kellaris, 1988), location and academic reputation are important determinants (Briggs, 2006).

Thus, our first hypothesis is that competition for students is, first, affected by the discipline structure, and, second, by distance. We notice that, as to the cost of enrollment, Italian universities are weakly differentiated and different price levels only occurs in few disciplines with many students.

Mobility of students is usually considered in the larger frame of migration processes. This literature shows that the decision to move is guided by investment motives, e.g. the will to improve employment opportunities and income, and consumption motives, e.g. looking for a better location, with more cultural activities, etc. Students tend to move to areas with higher university resources, producing a concentration of high-quality institutions in large cities (Ono, 2001), when intraregional availability of HEIs is high the migration is reduced (Mc Cann and Sheppard, 2002), students that live close to a given type of HEI will likely enroll in that type of institution (Ordorvensky, 1995). Gravity models have been used to estimate student flows and their determinants, considering the region or the institution as unit of analysis. Mc Hugh and Morgan (1984) model the decision of students to migrate as a function of institutional variables and distance. Two measures of distance are used, as the 'crow flies' and as the mean distance with all other states in order to consider the impact of alternatives, and they both show a negative effect. Institutional quality has mixed effects because it is important for some, whereas other students opt for less selective college. In a study of Japan HE system, a production-constrained gravity model showed that the distance had a negative effect whereas the chances of an individual to choose a given university increases when other universities are close, showing an agglomeration effect (Ishikawa, 1987). Selective universities in the USA attract more non-resident students (Baryla and Dotterweich, 2001). In a study of the Dutch attractiveness of universities, the behavior of prospective students shows a negative impact of distance and rent, whereas regional and urban amenities have a stronger positive effect than educational quality and programs (Sá et al., 2004).

Thus, given the cost of mobility, we expect a concentration of students flows toward the most densely populated and accessible area, i.e. the city of Milan. Moreover, high reputation is expected to increase attractiveness especially of mobile students, because attending a reputed university is an added value that compensates the cost of moving. 
A third hypothesis is that the structure of competition will be related to the number of regional students in that field: the more they are and the more the potential actors and differentiation in supply. In fact, opening a course is costly and it is only convenient when there are a sufficient number of potential students. When the number of students is small, courses will be offered only in central and populated areas.

\section{Case study and empirical tests}

Two measures of cooperation in research are considered: (i) research projects and (ii) co-publications. We study the patterns of successful co-application for grants assigned by the Italian Ministry of Education on a competitive basis $\left(\right.$ PRIN projects $\left.{ }^{1}\right)$. These projects have mostly a disciplinary, fundamental-research orientation and they are promoted in all scientific fields. Each project has a leadership unit (Principal) and one or more secondary units. Data on PRIN projects from 2000 and 2008 are from sources the Italian Ministry of Education (http://PRIN .miur.it/; http://datiPRIN.cineca.it/), whereas co-publication data are extracted from the ISI web of Science (2000-10). This database is positively biased toward hard sciences and medicine, whereas social science and humanities are less covered.

We model counts of collaborations through a negative binomial regression. The dependent variable is the number of projects in collaboration between university $x$ and university $y$ where university $x$ is a principal and university $y$ a secondary unit. Since the number of dyads with no collaborations is high ( $35 \%$ of the sample), we employ a hurdle negative binomial regression, which specifies a separate model for predicting zeros (Mullahy, 1986). A similar model is used for the analysis of co-authorships. As the number of dyadic relationship with no co-authorships is small, a simple negative binomial regression model (no hurdle) has been employed.

As to teaching, the relational arena is studied through the analysis of flows of regional students, using data from the Italian Ministry of Education. We study student flows by using production-constrained gravity models, which are suitable when the number of students originating in each zone is fixed. The equation is linearized by taking logarithms of both sides and rearranging (Fotheringham and O'Kelly, 1989; Sá et al., 2004).

$$
\ln T_{i j}-(1 / n) \sum \ln T_{i j}=\sum_{h} \alpha_{h}\left[\left(w_{j h}\right)-(1 / n) \sum\left(w_{j h}\right)\right]
$$

where:

$T_{i j}$ is the fluxes of students from province $i$ to university $j$

$W_{j h}$ is the value of the university $j$ for the independent variable $h$

Table 1 summarizes the variables and the indicators used.

\subsection{The Lombardy system}

The analysis is developed on the HE system of Lombardy, the largest and wealthiest Italian region, which counts 9 million inhabitants and over 260 thousands students; we consider the 11 universities and 1 technical university, which include $96 \%$ of higher education students and almost all research activities in the regional higher education. Data on institutional features have been extracted from the EUMIDA database (Bonaccorsi et al., 2010).

Universities located in Lombardy vary considerably (Table 2). The number of students ranges between 2,400

Table 1. Variables and indicators employed in the regression tests

Variable Indicator

Size Number of academic staff

Discipline Discipline similarity: measures the extent to which the HEIs have a similar subject mix and ranges from ' 0 ', no similarity at all, to ' 1 ' same discipline profile. The share of students enrolled by each of the nine subject domains $(i->n)$ of educational statistics has been computed; the subject overlap between HEI ' $X$ ' and HEI ' $Y$ ' is given by the following formula: Subject Overlap $=\sum i=1$ - > 9 MIN $(X i ; Y i)$.

Scope of courses: measures the degree of coverage of the Lombardy HE market for education, and it is given by the formula: Courses Scope $=\sum i=1->9$ MKT_Di* $X i$; where MKT_Di is the share of Lombardy students enrolled in discipline $i$ and $X i$ equals ' 1 ' if university $X$ has courses in discipline $i$, and ' 0 ' if not.

Distance In minutes of time to travel to province capital city to the city of the university by public transportation (mainly train).

Productivity $\quad \mathrm{n}^{\circ}$ publication per unit of staff - source CWTS Leiden, ISI web of Science; it is a measure of relative productivity.

Reputation Excellence VTR, calculated in VTR 2004, the latest Italian research assessment exercise (CIVR, 2007). It is a measure of Research quality and a proxy of Reputation at the national level:Excellence VTR $=$ AVG $x_{1 \rightarrow n}$ [(property 'excellence $\left.x^{\prime}\right) /(\%$ of products submitted)]In VTR there where four scale of judgment, and 'excellent' was the highest rate. The property of those products was computed for each of the fields. We consider the average value in the ration between: the property of excellent products and the share of products submitted.

Research intensity $\mathrm{n}^{\circ} \mathrm{PhD} / \mathrm{n}^{\circ}$ graduate students - this is the most commonly used proxy of research intensity as it provides an indication of the effort spent in research compared to that in teaching.

Teaching intensity $\mathrm{n}^{\circ}$ students $/ \mathrm{n}^{\circ}$ academic staff - this indicator estimate the teaching burden of the academic staff.

Urbanization Population of the province, it is a proxy of the location amenities and attractiveness. 


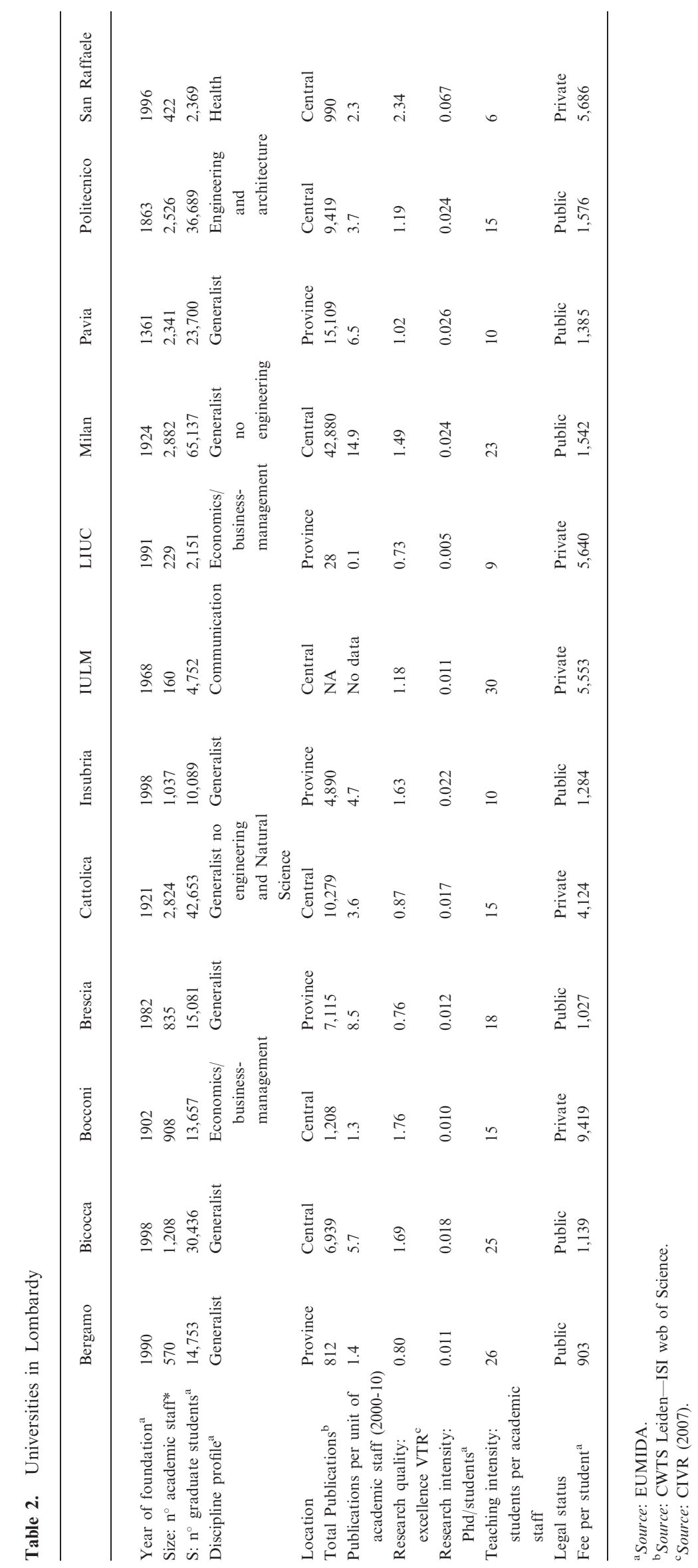




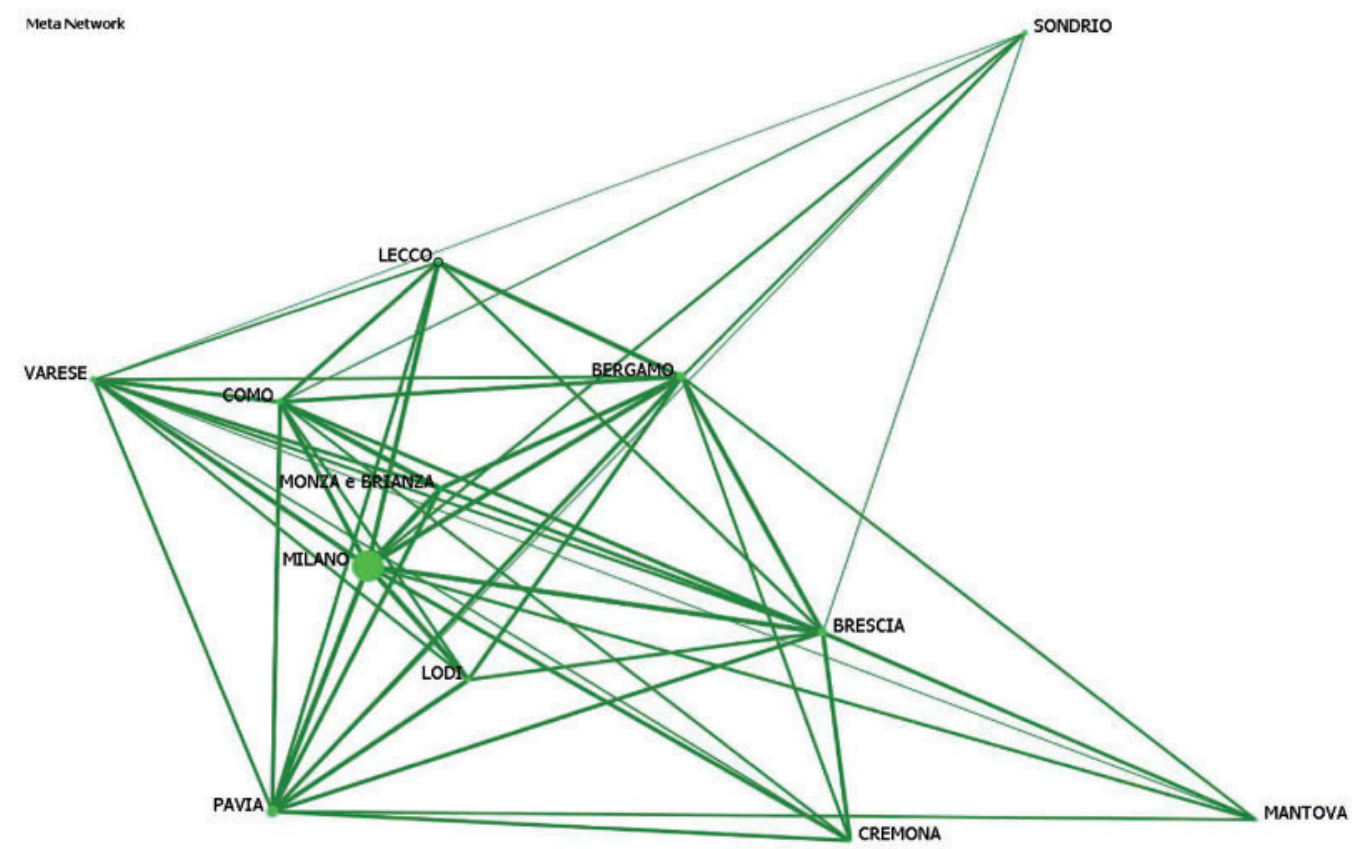

Figure 1. Lombardy: size of university agglomerations and distance-time between cities. Source: distance in time of train-www.trenitalia.it; students numbers-EUMIDA.

(San Raffaele) and 65,000 (Milan), and similar differences exist in the number of academic staff. Seven universities are generalist, while five are specialized; seven are public and five are private. The variability in the students-professors ratio is large, from 30 (IULM) to 6 (San Raffaele). Seven universities are located in the Milan metropolitan area and five in the provinces. The University of Milan is by large the most productive university, in relative and absolute terms; followed by Pavia, Politecnico, Bicocca, Brescia, Insubria and Bocconi, which also show a rather large scientific production.

The geography and system of transportation of the region is strongly centered around the city of Milan, with larger travel-time between second-level cities. Figure 1 synthetizes the capability to move across Lombardy: cities are approximately located in their geographic position, the width of the lines is inversely proportional to the travel-time, the nodes represent a province where there is at least a university and their size is proportional to the number of students enrolled. A total of $76 \%$ of the students are enrolled in Milan, a much higher share than the population living in that province $(31 \%)$, confirming a process of concentration of universities and students in the more central and accessible area.

It is important to remind that competition for students takes place at different geographical levels (regional, national, international). Nevertheless, this article focuses on the regional level, i.e. on the competitive relationships between Lombardy universities for Lombardy students. The rationale for this choice is that the level of mobility between regions and countries for undergraduate students is relatively limited: as a matter of fact, $77 \%$ of students in Lombardy universities come from the region, whereas $88 \%$ of students from Lombardy study in the region. This shows that Lombardy is an attractive region for external students, but competition from non-regional universities is limited. As a matter of fact, competition from outside the region is relevant only for the peripheral provinces, which have faster connection to cities outside the region than to Milan: the two universities with the largest number of students from the province of Mantova are Parma and Verona; the same applies, but a lesser extent for the province of Cremona. To sum up, the specific geographical structure of Lombardy and the attractiveness of Lombardy universities mean that external competition is in the aggregate of minor importance for studying competition for regional students.

\section{Relational arena in the Lombardy Higher Education System}

\subsection{An overall view of research cooperations}

We use three indicators to describe the position of each university in the research relational arena (Table 3). Regional involvement measures the relative degree of collaboration with regional partners, calculated as the share of projects/publications with at least one regional partner; the concentration index (Herfindahl index) is a proxy of concentration of the collaborations with Lombardy partners; finally, the leadership ratio measures the tendency of a university to play the role of leader in 
Table 3. Indicators for the description of the university position in the regional network of collaboration

\begin{tabular}{|c|c|c|c|c|c|}
\hline & \multicolumn{3}{|c|}{ Projects } & \multicolumn{2}{|c|}{ Publications } \\
\hline & $\begin{array}{l}\text { Regional } \\
\text { involvement (\%) }\end{array}$ & $\begin{array}{l}\text { Concentration } \\
\text { index }\end{array}$ & $\begin{array}{l}\text { Leadership } \\
\text { ratio }\end{array}$ & $\begin{array}{l}\text { Regional } \\
\text { involvement (\%) }\end{array}$ & $\begin{array}{l}\text { Concentration } \\
\text { index }\end{array}$ \\
\hline Bergamo & 70 & 0.20 & 0.9 & 12 & 0.23 \\
\hline Bicocca & 42 & 0.29 & 0.8 & 7 & 0.41 \\
\hline Bocconi & 41 & 0.15 & 1.5 & 9 & 0.27 \\
\hline Brescia & 53 & 0.20 & 0.5 & 8 & 0.24 \\
\hline Cattolica & 44 & 0.29 & 1.4 & 2 & 0.32 \\
\hline Insubria & 37 & 0.30 & 0.8 & 11 & 0.46 \\
\hline IULM & 33 & 0.30 & 0.7 & & \\
\hline LIUC & 43 & 0.35 & 0.4 & & \\
\hline Milan & 34 & 0.16 & 1.2 & 4 & 0.17 \\
\hline Pavia & 37 & 0.22 & 1.0 & 4 & 0.29 \\
\hline Politecnico & 33 & 0.20 & 2.2 & 5 & 0.26 \\
\hline San Raffaele & 34 & 0.39 & 7.4 & 4 & 0.50 \\
\hline
\end{tabular}

Source: PRIN project database; CWTS Leiden (ISI-web of Science), no data for IULM; very few data for LIUC.

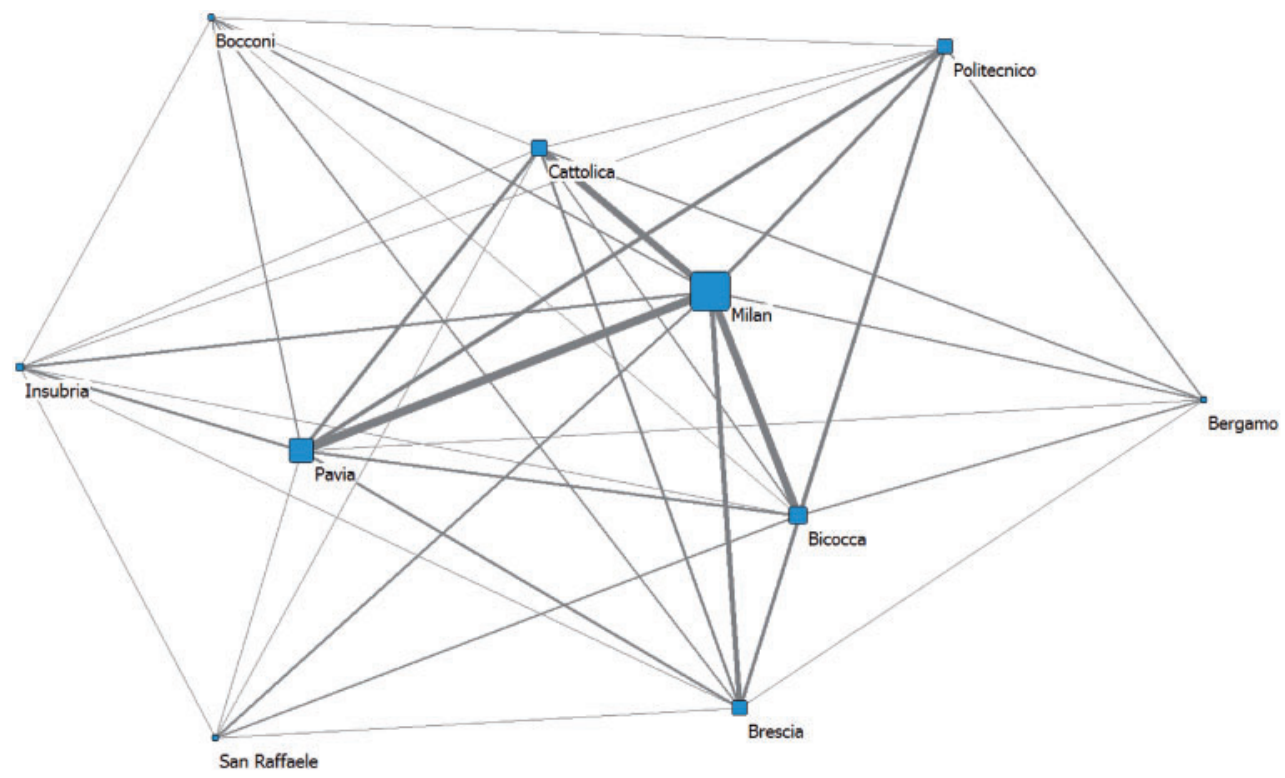

Figure 2. The regional network of PRIN collaborations.

Source: designed by the authors with UCINET (Borgatti et al., 2002) using PRIN project database. The position of the nodes is determined with the sPRINg-embedded function and 'distances' algorithm. The size of the nodes is proportional to the number of total projects in cooperation with Lombardy partners; the size of the lines is proportional to the number of projects cooperation. LIUC and IULM are not included, only marginal figures.

regional PRIN collaborations; it is calculated as the ratio between the number of projects in which a unit of the university is principal to the number of projects as secondary unit.

Expectedly, regional collaboration is much stronger for PRIN (38\%) than for publications $(5 \%)$. Some universities display a much higher level of regional orientation in collaborations: Bergamo $(70 \%)$ and Brescia $(53 \%)$ for PRIN, Bergamo (12\%) and Insubria $(11 \%)$ for co-publications.
In PRIN, the core of the system is represented by the University of Milan, the key player with over 400 projects, and by 3 large generalist universities (Pavia, Cattolica, and Bicocca); the partnerships between these four actors regroup $40 \%$ of the total cooperation. Strong players are also the Politecnico and Brescia, but they have less central positions. Brescia is overly dependent to Milan. The position of Politecnico is influenced by its discipline specialization: even if it is the third largest leader, it is rarely involved as a partner in projects (Fig. 2). We notice that 


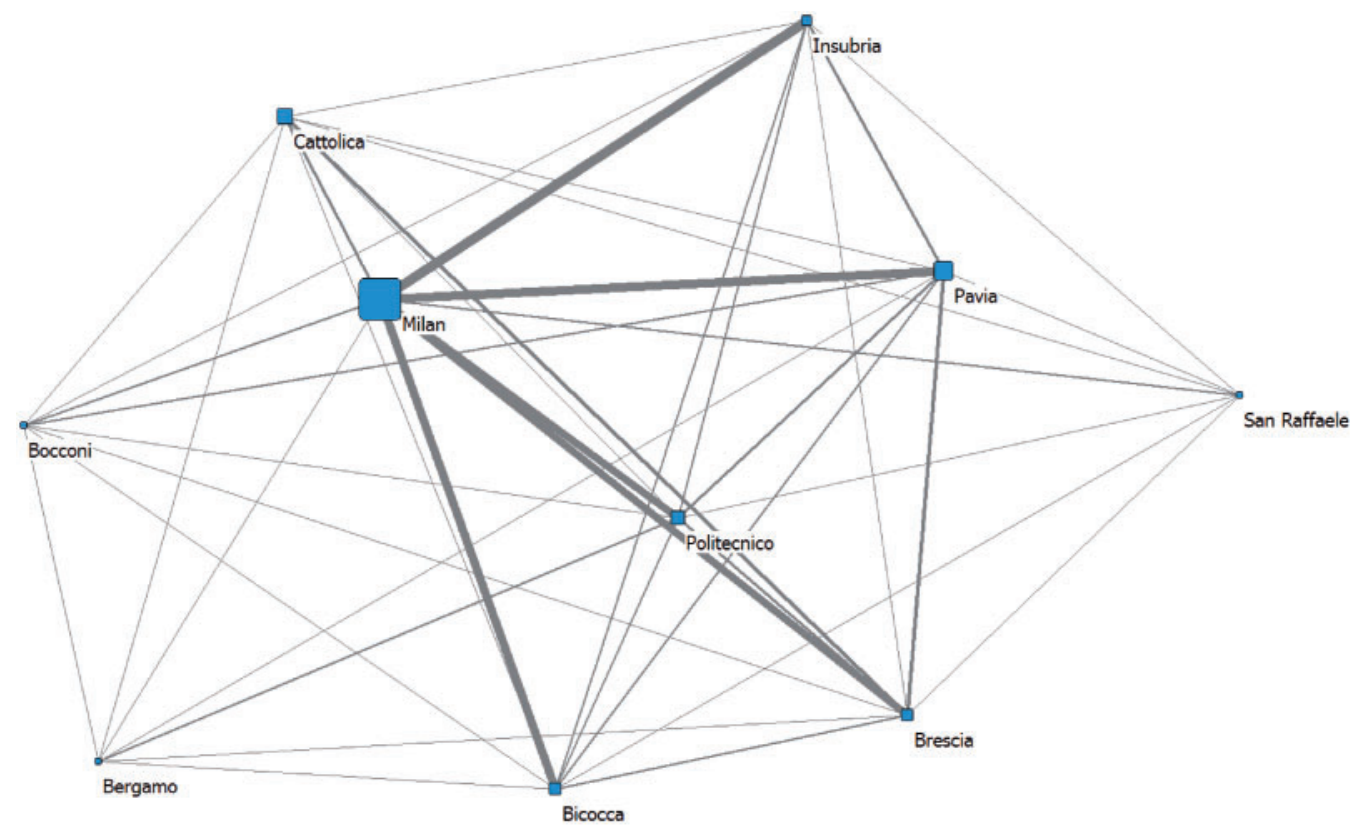

Figure 3. Network of co-publications in Lombardy Region.

Source: designed by the authors on Leiden CWTS data, with UCINET. The position of the nodes is determined with the sPRINg-embedded function and 'distances' algorithm. The size of the nodes is proportional to the number of total publications in cooperation with Lombardy partners; the size of the lines is proportional to the number of co-publications.

the relationships between the core actors are not only of large size, but also intense and rather balanced.

As to the co-publication network, the core is represented by Milan, Pavia, and Politecnico. In comparison to the PRIN, Politecnico assumes a more central position possibly because in co-publication its peculiar discipline profile is less relevant. Bicocca and Cattolica shift to a more peripheral position. In co-publications the connections between the central players represent only $27 \%$ of the total, whereas the relative majority of relationships (41\%) develop between Milan and more peripheral actors, which tend to be of lower standing and seem to have in Milan a point of reference: Insubria, Bicocca, and Brescia (Fig. 3).

\subsubsection{Patterns and determinants of research} collaboration. Table 4 presents the results of the hurdle negative binomial regressions for PRIN collaborations. The full model including productivity and distance is significantly better than the one with size and discipline only $\left(\chi^{2}\right.$ value of 46 with $\left.4 \mathrm{df} ; \mathrm{P}>0.0001\right)$. The other variables tested are not significant.

Size and scientific productivity are the most important factor affecting the probability and number of the project cooperation. Discipline similarity is significant for the likelihood of being connected, but not for the number of cooperation, while there is limited evidence of an impact of distance (the coefficient being marginally significant only for the likelihood of being connected). Table 5 shows the relative impact of each variable in the complete model.
Table 6 illustrates the results of the regression model for co-authorships. Also in this case, the full model is significantly better than the model including only size and discipline similarity. Results are quite similar to projects, except that discipline and distance are not significant at all.

Table 7 shows the relative impact of each variable in the complete model.

By summarizing, regressions show that the main predictors of collaboration in both cases are size and productivity of the cooperating institutions, while other variables such as research intensity and national reputation are not significant. Discipline similarity is of some importance for project collaboration, but not for co-authorships - but this might be due to the small size of the sample and its specific composition.

For project collaboration, there is weak evidence that distance reduces the chances for collaboration, likely because coordination and frequent interactions are needed, whereas in co-publications geographical distance does not matter at all. The different role of distance has a weak, yet apparently important influence on collaboration patterns between the central and the peripheral universities. In PRIN, the collaboration are concentrated between central actors, whereas in publications there is a propensity to establish cooperation on a center-periphery direction, likely because many researchers' career develop along this axe and influence collaboration patterns as well: they get a $\mathrm{PhD}$ or similar in a central university, in the first stage of career they work in peripheral universities and possibly, after some years, return in a central university. 
Table 4. Hurdle negative binomial regression models ${ }^{\mathrm{a}}$

\begin{tabular}{|c|c|c|c|c|c|c|}
\hline & \multicolumn{3}{|c|}{ Size and discipline (1) } & \multicolumn{3}{|c|}{ Complete model (2) } \\
\hline & Estimate & Std. Error & $\operatorname{Pr}$ & Estimate & Std. Error & $\operatorname{Pr}$ \\
\hline (Intercept) & -0.98 & 0.36 & $* *$ & -0.90 & 0.37 & * \\
\hline Academic staff total $x+y$ & 0.0007 & 0.0001 & $* * *$ & 0.0005 & 0.0001 & $* * *$ \\
\hline Discipline similarity & 1.02 & 0.50 & * & 0.59 & 0.49 & \\
\hline Distance $x-y$ & & & & 0.00001 & 0.005 & \\
\hline Relative productivity $x$ & & & & 0.079 & 0.02 & $* *$ \\
\hline Relative productivity $y$ & & & & 0.085 & 0.03 & $* * *$ \\
\hline Log (theta) & 0.17 & 0.33 & & 0.74 & 0.31 & * \\
\hline \multicolumn{7}{|c|}{ Zero hurdle model coefficients (binomial with logit link) } \\
\hline (Intercept) & -3.91 & 0.72 & $* * *$ & -5.07 & 0.94 & $* * *$ \\
\hline Academic staff total $x+y$ & 0.0013 & 0.0002 & $* * *$ & 0.0011 & 0.0003 & $* * *$ \\
\hline Discipline similarity & 2.88 & 1.04 & $* *$ & 4.01 & 1.32 & ** \\
\hline Distance $x-y$ & & & & -0.02 & 0.01 & * \\
\hline Relative productivity $x$ & & & & 0.24 & 0.10 & * \\
\hline Relative productivity $y$ & & & & 0.41 & 0.11 & $* * *$ \\
\hline Theta: count & & 1.18 & & & 2.08 & \\
\hline Number of iterations & & 10 & & & 15 & \\
\hline Log-likelihood & & -296 on $9 \mathrm{df}$ & & & -273 on $13 \mathrm{df}$ & \\
\hline
\end{tabular}

Signif. codes: 0 '***' 0.001 '**' 0.01 '*' 0.05 ' .0 .1 ' '1.

${ }^{a}$ Intensity of connection in the section above, whereas comparison between active and non-active connection is in the section below.

Table 5. Hurdle negative binomial regression model: comparing the impact of the variables

Expected change

Variable

Delta
$+1,000$ units of staff +0.25 disc similarity
+50 min of shuttling
+5 publications
+5 publications

Academic staff total $x+y$

Discipline similarity

Distance $x-y$

Relative productivity $x$

Relative productivity $y$

\begin{tabular}{ll}
\multicolumn{2}{c}{ Expected change } \\
\hline $\begin{array}{l}\text { Proportion in } \mathrm{N}^{\circ} \\
\text { of co-projecting } x->y\end{array}$ & Likelihood of $x$ \\
& leading project with $y$
\end{tabular}

$\begin{array}{lll}1.6 & * * * & 2.9\end{array}$

$\begin{array}{ll}1.8 & 2.7\end{array}$

$\begin{array}{ll}1.0 & 0.4\end{array}$

$\begin{array}{lll}1.5 & * * * & 3.3\end{array}$

$\begin{array}{lll}1.5 & * * * & 7.9\end{array}$

\begin{tabular}{l}
$* *$ \\
$* *$ \\
$*$ \\
$* * *$ \\
$* * *$ \\
\hline
\end{tabular}

Table 6. Negative binomial regression models

\begin{tabular}{|c|c|c|c|c|c|c|}
\hline & \multicolumn{3}{|c|}{ Size and discipline (2) } & \multicolumn{3}{|c|}{ Complete model (3) } \\
\hline & Estimate & Std. Error & $\operatorname{Pr}$ & Estimate & Std. Error & $\operatorname{Pr}$ \\
\hline (Intercept) & -0.26 & 0.68 & & -0.02 & 0.54 & \\
\hline Total academic staff $x+y$ & 0.0009 & 0.0001 & $* * *$ & 0.0004 & 0.0001 & $* * *$ \\
\hline Discipline similarity & 1.53 & 0.78 & $*$ & -0.66 & 0.67 & \\
\hline Relative productivity $x$ and $y$ & & & & 0.40 & 0.05 & $* * *$ \\
\hline Distance $x-y$ & & & & 0.01 & 0.01 & \\
\hline Theta: count & & 0.67 & & & 1.02 & \\
\hline Number of iterations & & 1 & & & 1 & \\
\hline Log-likelihood & & -203.30 & & & -186.02 & \\
\hline
\end{tabular}

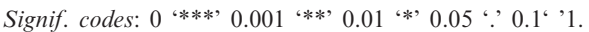


Table 7. Negative binomial regression model: comparing the impact of the variables

\begin{tabular}{|c|c|c|c|}
\hline \multirow[b]{2}{*}{ Variable } & \multirow[b]{2}{*}{ Delta } & \multicolumn{2}{|c|}{ Expected change } \\
\hline & & Pro & \\
\hline Total academic staff $x+y$ & $+1,000$ units of staff & 1.5 & $* * *$ \\
\hline Average relative productivity $x$ and $y$ & +5 publications per unit & 7.5 & $* * *$ \\
\hline
\end{tabular}

Table 8. Estimation results and beta values for the productionconstrained gravity model

\begin{tabular}{lccc}
\hline & \multicolumn{3}{c}{ Simple gravity model } \\
\cline { 2 - 4 } & Estimate & Std. Error & Pr \\
\hline & & & \\
(Intercept) & -1.64 & 0.19 & $* * *$ \\
Size: students uni $x$ & 0.00007 & 0.00001 & $* * *$ \\
Distance time & -1.28 & 0.18 & $* * *$ \\
Adjusted $R$ & & 0.58 & \\
P-value & & $<2.2 \mathrm{E}-16$ & \\
df & & 129 & \\
$F$ statistic & & 91.47 & $* * *$ \\
Beta values-full model & Simple gravity model & $* * *$ \\
Size: students uni $x$ & 0.61 & & \\
Distance time & -0.41 & \\
\hline
\end{tabular}

Signif. codes: 0 ‘***’ 0.001 '**’ 0.01 '*' 0.05 '? 0.1 ' '1.

\subsection{Teaching competition}

Concerning education, our data support the hypothesis that discipline is more important in determining student's choices than geographical distance.

Namely, if distance were more important students would prefer to enroll a second-best but closer faculty. Seemingly this is not the case as the presence of a faculty in a province does not increase the relative share of students in that field: instead students tend to enroll less in a faculty that is in the university of their city $(-1.9 \%$ compared with the regional average) and more to faculties that are not $(+0.9 \%){ }^{2}$

Second, data show that mobility is substantial: namely, $44 \%$ of Lombardy students are enrolled outside of their province and it is not only determined by subject specialization- $19 \%$ of students enroll out of their province despite the fact that the faculty exists in their province of origin. Table 8 presents the results of a regression with a gravity model based on the size of the university of destination and the distance time. ${ }^{3}$ Both factors are highly significant and have the expected sign, thus leading to a strong concentration of students in the central and more accessible areas.

We also tested the hypothesis that students are more likely to move when they perceive that the cost of moving is compensated by a better quality of the university of destination. However, university-level measures of quality are not significant. This may be explained by the fact that aggregated measure of quality, are particularly weak in the Italian system, where there is much more variation in the quality of departments within the same university than between universities as a whole (Abramo et al., 2011).

Following our argument that the analysis of the fluxes of students is more appropriate at the field level, a second set of tests explores a highly competitive field, Economics and Management (Table 9). The first model includes the size and the distance, the full model also includes a measure of quality based on the national evaluation exercise; finally, the full model is tested on the subset of mobile students, in order to investigate the interaction between distance and reputation on enrolment decision.

Results confirm the explanatory power of the variables and that reputation is particularly valuable for mobile students; in fact, most of the positive impact of reputation and its significance in the full model is generated by the mobile students ( 73 cases versus 80 of non-mobile). Thus our data support the hypothesis that students' choices are driven by reputational consideration of the university in that specific field rather than by universitylevel quality.

Finally, Table 10 provides evidence supporting the hypothesis that the structure of competition and the number of competitors is related to the number of students by field.

Each field corresponds to the 17 faculties codified by the Italian Ministry of Education's Statistical Office.

Fields below 10,000 students are characterized by monopolies, quasi-monopolies, and duopolies. With very few exceptions, these disciplines are covered only by large generalist universities located in highly populated areas. In disciplines with more than 10.000 regional students other structures emerge, with a center of large players and a periphery of smaller universities with the characteristics of geographic or discipline specialists. The number of students is strongly correlated to measures of competition, such as Herfindahl Concentration $(-0.72)$ and Net Mobility $(+0.86)$. The only notable exception is represented by Engineering, where Politecnico maintains a quasi-monopolistic position: for more than a decade a net of seats in peripheral provinces have been created in order to 'protect' the regional basin of students and to 
Table 9. Estimation results and beta values for the production-constrained gravity model in Economics

\begin{tabular}{|c|c|c|c|c|c|c|c|c|c|}
\hline & \multicolumn{3}{|c|}{ Simple gravity model } & \multicolumn{3}{|c|}{ Full model } & \multicolumn{3}{|c|}{ Full model—mobile students } \\
\hline & Estimate & Std. Error & $\operatorname{Pr}$ & Estimate & Std. Error & $\operatorname{Pr}$ & Estimate & Std. Error & $\operatorname{Pr}$ \\
\hline (Intercept) & 0.00 & 0.15 & & 0.00 & 0.15 & & 0.12 & 0.17 & \\
\hline Size: students uni $x$ in Economics & 0.96 & 0.28 & $* *$ & 0.57 & 0.30 & & 0.31 & 0.40 & \\
\hline Distance time & -2.00 & 0.22 & $* * *$ & -1.98 & 0.22 & $* * *$ & -2.46 & 0.44 & $* * *$ \\
\hline Reputation: excellence VTR & & & & 1.27 & 0.44 & $* *$ & 1.30 & 0.47 & ** \\
\hline Adjusted $R$ & & 0.62 & & & 0.65 & & & 0.59 & \\
\hline P-value & & $<2.2 \mathrm{E}-16$ & & & $<2.2 \mathrm{E}-16$ & & & $<5.8 \mathrm{E}-15$ & \\
\hline df & & 81 & & & 80 & & & 73 & \\
\hline$F$ statistic & & 69.17 & & & 53.01 & & & 38.19 & \\
\hline Beta values & Simple gr & avity model & & & Full model & & Full mod & - mobile students & \\
\hline Size: students uni $x$ in Economics & & .25 & $* *$ & & 0.15 & & & 0.08 & \\
\hline Distance time & & 0.66 & $* * *$ & & -0.65 & $* * *$ & & -0.59 & $* * *$ \\
\hline Reputation: excellence VTR & & & & & 0.21 & $* *$ & & 0.23 & $* *$ \\
\hline
\end{tabular}

Signif. codes: 0 ‘***' 0.001 '**' 0.01 '*' 0.05 '? 0.1 ' '1.

Table 10. Discipline segmentation

\begin{tabular}{|c|c|c|c|c|c|}
\hline Faculty & $\begin{array}{l}\text { Students from } \\
\text { Lombardy }\end{array}$ & Form of the relational arena & $\begin{array}{l}\text { Concentration } \\
\text { index }\end{array}$ & $\begin{array}{l}\text { Internal } \\
\text { mobility* }(\%)\end{array}$ & $\begin{array}{l}\text { NET internal } \\
\text { mobility** }(\%)\end{array}$ \\
\hline \multicolumn{6}{|l|}{ Small disciplines } \\
\hline Statistics & 448 & Monopoly & 1.00 & 44 & 0 \\
\hline Physical education & 899 & Monopoly & 1.00 & 52 & 0 \\
\hline Veterinary medicine & 1,833 & Monopoly & 1.00 & 60 & 0 \\
\hline Agriculture & 2,353 & Quasi-monopoly or duopoly & 0.77 & 69 & 0 \\
\hline Sociology & 2,648 & Quasi-monopoly or duopoly & 0.53 & 49 & 0 \\
\hline Psychology & 4,691 & Quasi-monopoly or duopoly & 0.39 & 44 & 5 \\
\hline Pharmacy & 4,840 & Quasi-monopoly or duopoly & 0.65 & 59 & 11 \\
\hline Languages & 7,236 & Quasi-monopoy or duopoly & 0.44 & 50 & 7 \\
\hline Architecture & 8,608 & Monopoly & 1.00 & 62 & 0 \\
\hline Political science & 9,621 & Quasi-monopoly or duopoly & 0.65 & 44 & 5 \\
\hline \multicolumn{6}{|l|}{ Large disciplines } \\
\hline Education & 11,190 & Oligopoly & 0.34 & 53 & 12 \\
\hline Medicine & 15,066 & Competitive segment & 0.22 & 60 & 27 \\
\hline Maths, physics, chemistry, biology & 15,258 & Oligopoly & 0.31 & 52 & 14 \\
\hline Law & 17,605 & Competitive segment & 0.19 & 32 & 22 \\
\hline Literature and philosophy & 22,129 & Oligopoly & 0.39 & 47 & 15 \\
\hline Engineering & 24,056 & Quasi-monopoly or duopoly & 0.47 & 47 & 26 \\
\hline Economics - management & 26,233 & Competitive segment & 0.15 & 31 & 20 \\
\hline
\end{tabular}

*Percentage of Lombardy students who study out of their province.

**Percentage of students who move despite the faculty exists in the HEI of their province.

Source: designed by the authors on Eumida and Miur data.

cover training needs in provinces with a strong manufacturing orientation.

4.2.1 Positions in the teaching relational space. By combining these results, three main groups of universities can be identified, with peculiar position and competitive interactions.

Pavia and the three largest universities in Milan are large public generalists, which constitute the core of the system.
Pavia is geographically less central and its smaller, but it is a traditional university with a high reputation and thus able to attract distant students. In disciplines with a large number of students they compete with each other and with geographic specialists for students of the peripheral provinces. In disciplines with a small number of students they often enjoy a position of monopoly or quasi-monopoly. The potential competition is expected to be high; nevertheless, these HEIs have partially distinct positions in the resource arena, protecting them from a direct pressure. 
Bicocca has a relative low student overlap ${ }^{4}$ with Milan (0.4) and Pavia (0.6); Cattolica has a different discipline approach and economic profile, which reduce the potential for competition. Milan and Pavia show a high overlap (0.9), but they are in different provinces and the fluxes are modest. Even lower are the fluxes toward geographic specialists. There is low or no overlap with Politecnico.

The geographic specialists (Bergamo, Brescia, and Insubria) are located in peripheral provinces, offer courses in fields with many students and they are never the largest actor in the discipline. They target students that do not have particular preferences or capability to spend, which 10-15 years ago would have studied in Milan but now have a closer supply. Geographic specialists manage to retain $42 \%$ of the students from their provinces, which represents $81 \%$ of their total students; but $58 \%$ move to another province (mostly Milan). They do not compete with each other (only 3\% study in another geographic specialist), while $41 \%$ study in a central generalist, $15 \%$ in discipline specialists (12\% in Politecnico).

The group of discipline specialists includes private, specialized universities located in the most densely populated areas (IULM, LIUC, Bocconi, and San Raffaele). They manage to fill specific and sufficiently distinct niches that grant them less pressure from other segments. The Politecnico is a peculiar player that dominates its two specialization disciplines. It has almost no competitors at the regional level and attracts a considerable number of students from other regions. Its strength derives from the geographical position, the large barriers to entry in Engineering and in Architecture, the reputation and a purposeful strategy of spatial location.

\section{Final discussion: main features and interactions between relational domains}

Before discussing the main results of the article, it is important to acknowledge some of limitations. We only considered teaching and research, whereas other activities such as doctoral education and the 'third mission' were not analysed. Organizational relationships have been analysed through aggregated measures at individual, group, or faculty levels, whereas we did not consider top-level strategic cooperation; finally, we could not investigate the role played by career patterns across regional institutions as a factor explaining inter university collaboration.

Moreover, the work was developed on a regional context that indeed shows some peculiarities. The national higher education system is strongly oriented toward equality, and the mobility of researchers and students is rather low. As a matter of fact, HE and research policy in Italy are mostly in the hand of the national government. At present most regions lack an explicit policy, but they are supposed to acquire more duties and expertize in HE management in the coming years; accordingly, developing methodologies for regional-level analysis is expected to become increasingly important in the next years.

Despite the mentioned limitations, this work presents some novelties in respect to previous studies on higher education indicators and relations.

We used an integrated approach for the study of the relational arenas combining several measures and analyses of the two spaces and their interactions. The choice of the regional context is motivated by substantive and practical reasons: we showed that the region is the central level for investigating competitive relationships in the educational arena and this also allows to consider interactions between education and research. Further, for a paper aiming to develop new indicators the regional level was convenient because of data availability and of the limited number of actors (allowing a more in-depth analysis of individual cases). An extension of this approach to whole countries would be highly interesting we notice that Lombardy has the size of many medium-sized countries in Europe.

We provide some evidence about the forces shaping and constraining competitive and cooperative relationship in a regional context. Research relationships are mostly determined by the size of the university and its level of productivity, with only a minor impact of distance for projects collaboration; competitive patterns in education are strongly driven by disciplinary fields, with a major role of geographical factors (in terms of centrality in the transportation system and concentration of population) and of size, while reputation matters only at the disciplinary level.

Apparently, the factors affecting the research and teaching arenas are quite different. However, a closer look shows strong interactions between the two domains, mediated by geography, regulation, and funding arrangements.

In a system of mass education that is weakly differentiated there are low motivation for students mobility, especially in a regional context where the socio-economic conditions are rather homogeneous. As a consequence highly populated areas see the emergence of most universities. Three phenomena further strengthen the concentration: (i) the agglomeration force and the propensity of students to move where most universities are located (Ishikawa, 1987; Ono, 2001); (ii) when the system is undifferentiated the perception of reputation tend to be correlated with size, thus further increasing the attractiveness of large universities; and (iii) the highly populated area of Milan is also the better connected to the transportation system.

Larger universities also receive more funding as, despite recent attempts to introduce more performance-based criteria, the lump-sum State allocation to Italian universities has been largely determined by the size of the institution and the number of students (Seeber, 2009). 


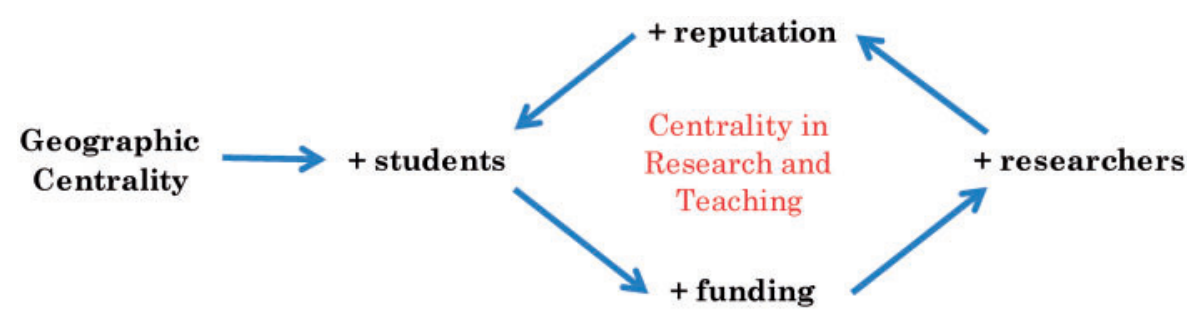

Figure 4. Interactions and dynamics between relational arenas.

This implies that the teaching arena indirectly but strongly affect the research arena, so that a university should have a large number of students to be central in the research arena (Fig. 4). This mechanism consolidates the centrality of large-central universities, but represents an obstacle to international competitiveness in research, as it makes differentiation concerning research quality and intensity largely impossible (as confirmed by available data on Italian universities; Bonaccorsi, 2009). On the contrary, other European HE systems show a reduced teaching burden on research universities because of the existence of a non-university sector absorbing part of the students (in binary systems; Kyvik and Lepori, 2010) or because the funding system allows the concentration of research funding on the best research performing universities (UK); as a result, in such systems research universities can invest a larger share of resources and efforts in research and the system becomes more differentiated.

Understanding and managing the driving forces and interplays of the relational arenas appears very important also for the universities: to improve their positioning and identify the better opportunities for development. First, the discipline' number of students affects the possibility for the emergence of new players and specialists. Second, only highly populated and central areas can sustain the emergence of specialists and large generalists: specialists are more likely to find an initial number of niche students sufficient to survival; and generalists can benefit from a larger basin of students and better accessibility. Third, the existing allocation system and geographic structure support the existing hierarchy based on size and geographical centrality rather than on research quality. Fourth, in Italy the same elements that gives large and central HEIs a strong competitive advantage versus smaller and peripheral ones, also limit their capability to compete in the international arena because they have to maintain high number of students and can hardly draw sufficient resources to increase research intensity.

The last contribution of the article consists in a few original positioning indicators that can be coupled with the more traditional indicators on activities and performance. Further work can be devoted to adapt and test other relational indicators already adopted by social network analysis, such as centrality and coreness measures.
In conclusion, there are three major lessons for higher education policies in general: first, the importance of taking into account cooperation patterns between universities when designing policies - and the related need to produce indicators on collaboration; second, the importance of geography in the relationships between universities; third, the fact that there are strong interactions between research and educational component of universities which might lead to some unexpected impacts of public policies and funding mechanisms.

\section{Acknowledgements}

We are grateful to the Lombardy Regional Government, which supported this work through a research grant. The opinions expressed in this article are our own.

\section{Notes}

1. Progetti di ricerca di interesse nazionale-Research projects of national priority.

2. We considered student in Bergamo, Brescia, Pavia, Como, and Varese, as Milan has all the faculties and the other provinces have none university headquarter.

3. Correlations between the variables in the models are not strong, the highest value occurring between Size and excellence in the test on Economics (0.48). Even though, we took several steps to test if multicollinearity poses a problem. First, the variance inflation factor is well below the recommended value of 10 (Kennedy, 1998). Second, if multicollinearity was a serious problem, even small changes in the sample could result in dramatic changes in the coefficient estimates (Fox, 1991). The models were therefore re-estimated after randomly eliminating $10 \%$ of the sample, with no significant changes of the results.

4. Students overlap, represents a proxy of potential competition: when two universities offer courses in the same faculties they have a higher ratio: $\left(\mathrm{N}^{\circ}\right.$ students of HEI $x$ in faculties existing in HEI $y$ ) / (total students HEI $x$ ). 


\section{References}

Abramo, G., Cicero, T. and D'angelo, C. A. (2011) 'The Dangers of Performance-Based Research Funding in Non-Competitive Higher Education Systems, Scientometrics, 87: 641-54.

Barnett, M. L. (2006) 'Finding a Working Balance Between Competitive and Communal Strategies', Journal of Management Studies, 43: 1753-73.

Baryla, J. D. R. and Dotterweich, D. (2001) 'Student Migration: Do Significant Factors Vary by Region?', Education Economics, 9: 269-80.

Bonaccorsi, A. (2009) 'Division of Academic Labour is Limited by the Size of the Market. Strategy and Differentiation of European Universities in Doctoral Education'. In: McKelvey, M. and Holmén, M. (eds) Learning to Compete in European Universities, pp. 90-127. Cheltenham: Edward Elgar.

Bonaccorsi, A. and Daraio, C. (2007) 'Theoretical Perspectives on University Strategy'. In: Bonaccorsi, A. and Daraio, C. (eds) Universities and Strategic Knowledge Creation. Specialization and Performance in Europe, pp. 3-30. Cheltenham: Edwar Elgar.

Bonaccorsi, A., Daraio, C., Lepori, B. and Slipersaeter, S. (2007) 'Indicators on Individual Higher Education Institutions: Addressing Data Problems and Comparability Issues', Research Evaluation, 16: 66-78.

Bonaccorsi, A. et al. (2010) Mapping the European Higher Education Landscape. New Insights from the EUMIDA project, Paper Presented at the Science and Technnology Indicators Conference, Leiden, 9-11.

Borgatti, S. P., Everett, M. G. and Freeman, L. C. (2002) Ucinet 6 for Windows.

Boschma, R. (2005) 'Proximity and Innovation: A Critical Assessment', Regional Studies, 39: 61-74.

Braun, T. and Glänzel, W. (1996) 'International Collaboration: Will it be Keeping Alive East European Research?', Scientometrics, 26: 147.

Breschi, S. and Lissoni, F. (2004) 'Knowledge Networks from Patent Data. In: Moed, H. F., Glänzel, W. and Schmoch, U. (eds) Handbook of Quantitative Science and Technology Research, pp. 613-44. Dordrecht: Kluwer.

Briggs, S. (2006) 'An Exploratory Study of the Factors Influencing Undergraduate Student Choice: the Case Study of Higher Education in Scotland', Studies in Higher Education, 31: 705-22.

Burt, R. S. (1992) Structural Holes: The social Structure of Competition. Cambridge, MA: Harvard University Press.

Carroll, G. R. and Hannan, M. T. (2000) The Demography of Corporations and Industries. Princeton, NJ: Princeton University Press.

Chapman, D. W. (1981) 'A Model of Student College Choice', Journal of Higher Education, 52: 490-505.

Coccari, R. L. and Javalgi, R. G. (1995) 'Analysis of Students' Needs in Selecting a College or University in a Changing Environment', Journal of Marketing for Higher Education, 6: 27-39.

Cummings, J. N. and Kiesler, S. (2005) 'Collaborative Research Across Disciplinary and Organizational Boundaries', Social Studies of Science, 35: 703-22.

(2007) 'Coordination Costs and Project Outcomes in Multi-University Collaborations', Research Policy, 36: 1620-34

de Boer, H., Enders, J. and Leisyte, L. (2007) 'Public Sector Reform in Dutch Higher Education: the Organizational Transformation of the University', Public Administration, 85: $27-46$
Deiaco, E., Holmén, M. and McKelvey, M. (2010) 'What Does it Mean Conceptually that Universities Compete?'. In: McKelvey, M. and Holmén, M. (eds) Learning to Compete in European Universities, pp. 300-28. Cheltenam: Edward Elgar.

Evans, T. S., Lambiotte, R. and Panzarasa, P. (2011) 'Community Structure and Patterns of Scientific Collaboration in Business and Management', Scientometrics, 89: 381-96.

Fotheringham, A.S. and O'Kelly, M.E. (1989) Spatial Interaction Models: Formulations and Applications. Dordrecht, The Netherlands: Kluwer Academic Publishing.

Fox, J. (1991) Regression Diagnostics. Newbury Park, CA: Sage.

Frenken, K., Hardeman, S. and Hoekman, J. (2009) 'Spatial Scientometrics: Towards a Cumulative Research Program', Journal of Infometrics, 3: 222-32.

Glänzel, W. (2001) 'National Characteristics in International Scientific Co-authorship', Scientometrics, 51: 69-115.

Glänzel, W. and Schubert, A. (2004) 'Analysing Scientific Networks Through Co-Authorship'. In: Moed, H. F., Glänzel, W. and Schmoch, U. (eds) Handbook of Quantitative Science and Technology Research, pp. 257-76. Dordrecht: Kluwer.

Gulbrandsen, M. and Slipersaeter, S. (2007) 'The Third Mission and the Entrepreneurial University Model'. In: Bonaccorsi, A. and Daraio, C. (eds) Universities and Strategic Knowledge Creation. Specialization and Performance in Europe, pp. 112-43. Cheltenham: Edward Elgar.

Hagstrom, W. O. (1965) The Scientific Community. New York: Basic Books.

Halffman, W. and Leydesdorff, L. (2010) 'Is Inequality Among Universities Increasing? Gini Coefficients and the Elusive Rise of Elite Universities', Minerva, 48: 55-72.

Hannan, M. T. and Freeman, J.(1989) Organizational Ecology. Cambridge, MA: Harvard University Press.

Hoskisson, R. E., Hitt, M. A., Wan, W. P. and Yiu, D. (1999) 'Swings of a Pendulum: Theory and Research in Strategic Management', Journal of Management, 25: 417-56.

Hossler, D. and Gallagher, K. (1987) 'Studying Student College Choice: A Three-Phase Model and the Implications for Policymakers', College and University, 62: 207-21.

Ingram, P. and Yue, L. Q. (2008) 'Structure, Affect and Identity as Bases for Organizational Competition and Cooperation', The Academy of Management Annals, 2: 275-303.

Ishikawa, Y. (1987) 'An Empirical Study of the Competing Destinations Model Using Japanese Interaction Data', Environment and Planning, 19: 1359-73.

Jones, B. F., Wuchty, S. and Uzzi, B. (2008) 'Multi-University Research Teams: Shifting Impact, Geography, and Stratification in Science', Science, 322: 1259-62.

Kellaris, J. J. and Kellaris, J. W. K. (1988) 'An Exploration of the Factors Influencing Students' College Choice Decision at a Small Private College', College and University, 63: 187-97.

Kennedy, P. (1998) A Guide to Econometrics. Oxford: Blackwell.

Klein, J. T. (2008) 'Evaluation of Interdisciplinary and Transdisciplinary Research - A Literature Review, American Journal of Preventive Medicine, 113: 116-23.

Kyvik, S. and Lepori, B. (2010) Research in the Non-University Higher Education Sector in Europe. Dordrecht: Springer.

Lee, S. and Bozeman, B. (2005) 'The Impact of Research Collaboration on Scientific Productivity', Social Studies of Science, 35: 673-702.

Maringe, F. (2006) 'University and Course Choice: Implications for Positioning, Recruitment and Marketing', International Journal of Educational Management, 20: 466-79.

Mc Cann, P. and Sheppard, S. (2002) 'An analysis of the gender determinants of UK graduate migration behaviour', Paper 
presented at the 42nd Congress of the European Regional Science Association, Dortmund, 27-31 August, 2002.

Mc Hugh, R. and Morgan, J. N. (1984) 'The Determinants of Interstate Student Migration: A Place-to-Place Analysis', Economics of Education Review, 3: 269-78.

Mulkay, C. F. M. (1972) 'Cultural Growth in Science'. In: Barnes, B. (ed.) Sociology of Science, pp. 126-42. Harmondsworth: Penguin.

Mullahy, J. (1986) 'Specification and Testing of Some Modified Count Data Models', Journal of Econometrics, 33: 341-65.

Newman, M. E. J. (2004) 'Coauthorship Networks and Patterns of Scientific Collaboration', Proceedings of the National Academy of Sciences of the United States of America, 101: 5200-5.

Noyons, E. C. (2004) 'Science Maps within a Science Policy Context'. In: Moed, H. F., Glänzel, W. and Schmoch, U. (eds) Handbook of Quantitative Science and Technology Research, pp. 237-55. Dordrecht: Kluwer Academic Publishers.

Olson, G. M. and Olson, J. S. (2000) 'Distance Matters', Human-Computer Interaction, 15: 139-78.

Ono, H. (2001) 'Migration patterns among Japanese university students', Paper presented at the Center for Economic Policy Research Conference of the European Network on Japanese Economy, Oxford, 17-18 March 2001.

Ordorvensky, J. F. (1995) 'Effects of Institutional Attributes on Enrollment Choice: Implications for Postsecondary Vocational Education?', Economics of Education Review, 14: 335-50.

Rivera, M. T., Soderstrom, S. B. and Uzzi, B. (2010) 'Dynamics of Dyads in Social Networks: Assortative, Relational, and Proximity Mechanisms', Annual Review of Sociology, 36: 91-115.
Sá, C., Florax, R. J. G. M. and Rietveld, P. (2004) 'Determinants of the Regional Demand for Higher Education in The Netherlands: A Gravity Model Approach', Regional Studies, 38: 375-92.

Schubert, A. and Braun, D. (1990) 'International Collaboration in the Sciences 1981-1985', Scientometrics, 19: 3-10.

Seeber, M. (2009) 'Changes in the governance of the Italian Higher Education system, the role of evaluation and funding as steering tools of research'. $\mathrm{PhD}$ thesis, University of Chieti-Pescara, Italy.

Soutar, G. N. and Turner, J. P. (2002) 'Students' Preferences for University: A Conjoint Analysis', International Journal of Educational Management, 16: 40-5.

Stokman, F. (2011) 'The crucial role of cooperation and competition in social networks for science and technology indicators', Paper Presented at the ENID S\&T Conference, Rome, September 2011.

Trochim, W. M. et al. (2008) 'The Evaluation of Large Research Initiatives - A Participatory Integrative Mixed Methods Approach', American Journal of Evaluation, 29: 8-28.

Van Vught, F. (2009) Mapping the Higher Education Landscape. Towards a European Classification of Higher Education. Milton Keynes, UK: Springer.

Wagner, C. S. (2008) The New Invisible College. Washington, DC: Brookings Press.

Whitley, R. (1984) The Intellectual and Social Organization of the Sciences. Oxford: Clarendon Press.

Wuchty, S., Jones, B. F. and Uzzi, B. (2007) 'The Increasing Dominance of Teams in Production of Knowledge', Science, 316: $1036-9$. 